\title{
Solid Oxide Amperometric CO Sensor for Monitoring Exhaust Gas from Water Heater
}

\author{
Tatsumi Ishihara*, Phawachalotorn Armonat ${ }^{1}$, \\ Rie Kadowaki and Oravan Sanguanruang ${ }^{1}$ \\ Department of Applied Chemistry, Faculty of Engineering, Kyushu University \\ Motooka 744, Nishi-ku, Fukuoka 819-0395, Japan \\ ${ }^{1}$ School of Chemistry, Faculty of Science, Chulalongkorn University, Bangkok, Thailand
}

(Received October 16, 2009; accepted April 13, 2010)

Key words: amperometric sensor, $\mathrm{CO}$ sensor, $\mathrm{LaGaO}_{3}$ electrolyte

An amperometric $\mathrm{CO}$ sensor using a solid oxide electrolyte was studied and it was found that the oxygen pumping current increased with increasing $\mathrm{CO}$ concentration when using $\mathrm{Au}(10 \mathrm{wt} \%) / \mathrm{In}_{1.9} \mathrm{Sn}_{0.1} \mathrm{O}_{3}$ and $\mathrm{RuO}_{2}(10 \mathrm{wt} \%) / \mathrm{La}_{0.6} \mathrm{Sr}_{0.4} \mathrm{CoO}_{3}$ as the electrode catalysts and $\mathrm{La}_{0.9} \mathrm{Sr}_{0.1} \mathrm{Ga}_{0.8} \mathrm{Mg}_{0.2} \mathrm{O}_{3}$ as the electrolyte. Mixed potentials are also observed on this sensor upon exposure to $\mathrm{CO}$, and so changes in oxygen pumping current may be caused by the mixed potentials formed upon exposure to CO. Substitution of Ga in the $\mathrm{LaGaO}_{3}$ electrolyte with $\mathrm{Fe}$ is effective for increasing the sensitivity, and this sensor is almost insensitive to $\mathrm{CO}_{2}$ and $\mathrm{CH}_{4}$. As a result, it is expected that this sensor can be used for the detection of $\mathrm{CO}$ in exhaust gas from a small gas water heater without a flue line.

\section{Introduction}

Selective and reliable sensors for the detection of $\mathrm{CO}$ are a thrust area of sensor research these days. Detection of $\mathrm{CO}$ is strongly required from a safety point of view because of its high toxicity. Therefore, several types of $\mathrm{CO}$ sensor have been proposed and some have already become commercially available. ${ }^{(1)}$ Among them, a semiconductor-type sensor, mainly, $\mathrm{SnO}_{2}$ modified with additives, is widely used for monitoring $\mathrm{CO}$ in a room. ${ }^{(2-5)}$ However, the most serious issue of the semiconductor-type sensor is low selectivity. On the other hand, recently, the detection of $\mathrm{CO}$ in exhaust gas from a gas water heater has been strongly demanded following an accident caused by incomplete combustion. However, the application of a semiconductor-type CO sensor for monitoring the combustion state is highly difficult and there is a strong requirement for the development of an alternative $\mathrm{CO}$ sensor that is highly selective and can detect $\mathrm{CO}$ directly in an exhaust gas line. ${ }^{(1)}$

${ }^{*}$ Corresponding author: e-mail: ishihara@cstf.kyushu-u.ac.jp 
To meet this demand, a CO sensor using a solid-state electrolyte was proposed and studied intensively. ${ }^{(1)}$ Solid electrolyte-type gas sensors generally have better selectivity against the objective gas species. Therefore, an $\mathrm{O}_{2}$ sensor using yttria-stabilized $\mathrm{ZrO}_{2}$ has been used widely for monitoring $\mathrm{P}_{\mathrm{O} 2}$ in engine exhaust gas. ${ }^{(1)}$ However, gas species detected by such gas concentration-type sensor are limited by mobile ion species in the solid electrolyte. On the other hand, a mixed-potential-type sensor has been attracting much attention recently because of the wide range of detectable gas species. ${ }^{(6)}$ The detection mechanism of the mixed-potential-type sensor is based on the difference in electrode activity in response to oxidation and it can detect gas species that are different from mobile ion species in the solid electrolyte. Mixed-potential-type sensors have advantages of simple structure and high selectivity; therefore, this type of sensor is suitable for monitoring exhaust gas. To date, there have been many reports on the mixedpotential-type sensor. ${ }^{(7-10)}$ For example, Miura et al. reported the high sensitivity and selectivity to $\mathrm{CO}$ in exhaust gas atmosphere of the mixed-potential-type sensor. ${ }^{(11)}$ This type of sensor has also been proposed for hydrocarbon, $\mathrm{CO}$, and $\mathrm{NO}_{2}$, and at present, $\mathrm{Y}_{2} \mathrm{O}_{3}$-stabilized $\mathrm{ZrO}_{2}$ (YSZ) is the most popular electrolyte for this type of sensor. For the mixed-potential-type sensor, the difference in electrode catalyst for oxidation and reduction is important for achieving a high sensitivity; however, because of the insufficient oxide ion conductivity of YSZ, the operating temperature of the mixedpotential-type sensor becomes high, which is undesirable for achieving a large difference in electrode activity in the objective reaction. In our previous studies, we investigated the amperometric-type sensor on the basis of changes in the oxide ion pumping current in a $\mathrm{LaGaO}_{3}$-based oxide, and high sensitivity, as well as selectivity, is exhibited by this type of sensor against $\mathrm{CH}_{4}, \mathrm{C}_{3} \mathrm{H}_{6}$, and $\mathrm{NO}$ by choosing the electrode catalyst. ${ }^{(12-16)}$ Mixed potential is strongly related to the change in current for this sensor.

In this study, we investigated the amperometric $\mathrm{CO}$ sensor on the basis of the same detection mechanism, i.e., a combination of active and inactive electrode catalysts for $\mathrm{CO}$ oxidation. Since both electrodes were put in the same atmosphere and oxide ions are pumped to the electrode active in $\mathrm{CO}$ oxidation, it is expected that the amperometric sensor will show high selectivity and sensitivity to $\mathrm{CO}$ and be suitable for monitoring exhaust gas. In addition, by using the oxygen pumping current, the sensitivity was much improved.

\section{Experimental Methods}

A solid electrolyte of a $\mathrm{La}_{0.9} \mathrm{Sr}_{0.1} \mathrm{Ga}_{0.8} \mathrm{Mg}_{0.2} \mathrm{O}_{3}$ (denoted as LSGM) disk was prepared by sintering the LSGM powder, which was prepared by a conventional solid-state reaction method. ${ }^{17,18)}$ The diameter and thickness of the disk were 17 and $0.4 \mathrm{~mm}$, respectively, unless otherwise noted. For the preparation of the active and inactive electrodes, impregnation of metal nitrate on an oxide was generally used. $\mathrm{Au} / \mathrm{In}_{1.9} \mathrm{Sn}_{0.1} \mathrm{O}_{3}$ (ITO) (9:1) and $\mathrm{RuO}_{2} / \mathrm{La}_{0.6} \mathrm{Sr}_{0.4} \mathrm{CoO}_{3}$ (LSC) (1:9) were used as the inactive and active electrodes, respectively. ITO and LSC 64 were also prepared by the solid-state reaction method using metal nitrate or oxide as starting chemical reagents. Before preparation of the slurry, the electrode powder was calcined at $873 \mathrm{~K}$ for $6 \mathrm{~h}$. The slurry of the prepared 
$\mathrm{Au} / \mathrm{ITO}$ powder was painted on one face of the LSGM disk as the inactive electrode $(\square 5 \mathrm{~mm})$. On the other side, $\mathrm{RuO}_{2} / \mathrm{LSC} 64$ powder, which was prepared by mixing $\mathrm{RuO}_{2}$ with LSC by ball milling, was painted as the active electrode on another surface of the same size.

In the measurement assembly, the sensor element was placed in the gas flow chamber in which either reference air or sample $\mathrm{CO}$ in ppm mixed with air was fed at $100 \mathrm{~mL} / \mathrm{min}$. The change in current density was measured by the dc two-probe method, and $\mathrm{Pt}$ and $\mathrm{Au}$ wires were used as lead wires for the active and inactive electrodes, respectively. $\mathrm{Pt}$ and $\mathrm{Au}$ meshes were also used as current collectors for the active and inactive electrodes, respectively, and were set on the painted electrode using commercial $\mathrm{Pt}$ and $\mathrm{Au}$ pastes. In the amperometric mode, dc $1 \mathrm{~V}$ was always applied using a potentiostat/galvanostat (Hokuto Denko, HA301) as the $\mathrm{RuO}_{2} / \mathrm{LSC}$ electrode was always a positive one. The voltage and current were measured with a digital multimeter (Advantest, Model R645A) and/or digital electrometer (Advantest, Model R8240). The sensitivity of the sensor was defined as the current change against the $\mathrm{CO}$ concentration of one order of magnitude.

\section{Results and Discussion}

\subsection{Optimization of electrode combination}

Table 1 shows a summary of the effects of electrode combination on the sensitivity to $\mathrm{CO}$. The change in oxygen pumping current of this sensor is based on the difference in electrode activity in response to $\mathrm{CO}$ oxidation. Therefore, the sensitivity to $\mathrm{CO}$ is strongly affected by the electrode catalyst combination. In this study, Au or Au supported on metal oxide is generally used as the inactive electrode catalyst as it is a well-known inert metal. When $\mathrm{Pt}$, which is also a well-known active catalyst, was used, a change in oxygen pumping current upon exposure to $\mathrm{CO}$ was observed; however, the change in the current is always small. Therefore, $\mathrm{Pt}$ is not suitable as the active electrode catalyst for this study. On the other hand, it is observed that the electrode catalyst containing $\mathrm{RuO}_{2}$ always shows a large sensitivity, and therefore, $\mathrm{RuO}_{2}$ is suitable as an oxidation catalyst for $\mathrm{CO}$. In particular, the combination of $\mathrm{Au}$ and $\mathrm{RuO}_{2}$ shows a large sensitivity

Table 1

Effects of electrode combination on $\mathrm{CO}$ sensitivity at $673 \mathrm{~K}$.

\begin{tabular}{lclc}
\hline Electrode combination & $\begin{array}{c}\text { CO sensitivity } \\
(\mu \mathrm{A} / \text { decade })\end{array}$ & Electrode combination & $\begin{array}{c}\text { CO sensitivity } \\
(\mu \mathrm{A} / \text { decade })\end{array}$ \\
\hline $\mathrm{RuO}_{2} / \mathrm{LDC}-\mathrm{Pt} 10 \mathrm{wt} \%$ & - & $\mathrm{Au} / \mathrm{RuO}_{2}+\mathrm{LSC6} 4$ & 66.4 \\
$\mathrm{SSC} 55 / \mathrm{LDC}-\mathrm{Pt} 10 \mathrm{wt} \%$ & -4.2 & $\mathrm{Au} / \mathrm{RuO}_{2}+\mathrm{LSGF7364}$ & 26.9 \\
$\mathrm{Au} / \mathrm{LDC}-\mathrm{Pt} 10 \mathrm{wt} \%$ & 3.6 & $\mathrm{Au} / \mathrm{RuO}_{2}+\mathrm{SDC} \%$ & 8.0 \\
$\mathrm{Au} / \mathrm{RuO} 2$ & 3.7 & $\mathrm{ITO} / \mathrm{RuO}_{2}$ & 331.7 \\
$\mathrm{Au} / \mathrm{NiO}$ & -0.46 & $\mathrm{ITO} / \mathrm{RuO}_{2}+\mathrm{LSC6} 4$ & 379.5 \\
$\mathrm{Au} / \mathrm{LDC}-\mathrm{Pd} 10 \mathrm{wt} \%$ & 4.0 & $\mathrm{ITO}-\mathrm{Au} 10 \mathrm{wt} \% / \mathrm{RuO}_{2}+\mathrm{LSC} 64$ & 596.9 \\
$\mathrm{Au} / \mathrm{CuO}$ & 5.1 & & \\
\hline
\end{tabular}

Electrolyte: $\mathrm{La}_{0.9} \mathrm{Sr}_{0.1} \mathrm{Ga}_{0.8} \mathrm{Mg}_{0.2} \mathrm{O}_{3}$ 
to $\mathrm{CO}$. In addition, it is seen that the sensitivity to $\mathrm{CO}$ is much improved by loading $\mathrm{Au}$ on $\mathrm{In}_{1.9} \mathrm{Sn}_{0.1} \mathrm{O}_{3}$ (ITO). This enhancement effect by ITO could be explained on the basis of a high-dispersion state of $\mathrm{Au}$ and the improvement of the electrical conductivity by ITO, which is also a well-known transparent conductive material. Application of ITO to the electrode of the mixed-potential-type sensor was also reported. ${ }^{(19)}$ The sensitivity to $\mathrm{CO}$ is further enhanced by mixing $\mathrm{RuO}_{2}$ with $\mathrm{La}_{0.6} \mathrm{Sr}_{0.4} \mathrm{CoO}_{3}$, which is also reported to be highly active in the oxidation reaction. As a result, it is seen that $\mathrm{Au} / \mathrm{ITO}$ and $\mathrm{RuO}_{2} / \mathrm{LSC}$ are the most optimized combinations for inactive and active electrodes, respectively, among the electrodes examined in this study. The sensitivity of this sensor to $\mathrm{CO}$ is as high as ca. $600 \mu \mathrm{A} /$ decade of CO. Therefore, in the next part of this study, we focused on the sensing property of the sensor using $\mathrm{Au} / \mathrm{ITO}$ and $\mathrm{RuO}_{2} / \mathrm{LSC}$ combinations for the electrodes.

Figure 1 shows the current change of the optimized sensor as a function of $\mathrm{CO}$ concentration at different temperatures. Evidently, the current increases with increasing $\mathrm{CO}$ concentration at all the temperatures examined. This suggests that $\mathrm{CO}$ could be detected from the change in oxygen pumping current. Furthermore, the slope of the dependence increased with increasing temperature, and at $773 \mathrm{~K}$, the sensitivity of the sensor reached a value of $1,237 \mu \mathrm{A} /$ decade. The activity in response to $\mathrm{CO}$ oxidation is improved by increasing the operating temperature, and so the difference in activity in response to $\mathrm{CO}$ oxidation seems to improve as the operating temperature increases. Since a linear relationship is observed between current change and CO concentration between 100 and 1,000 ppm, it is anticipated that the detectable $\mathrm{CO}$ concentration range could be expanded to tens of ppm levels.

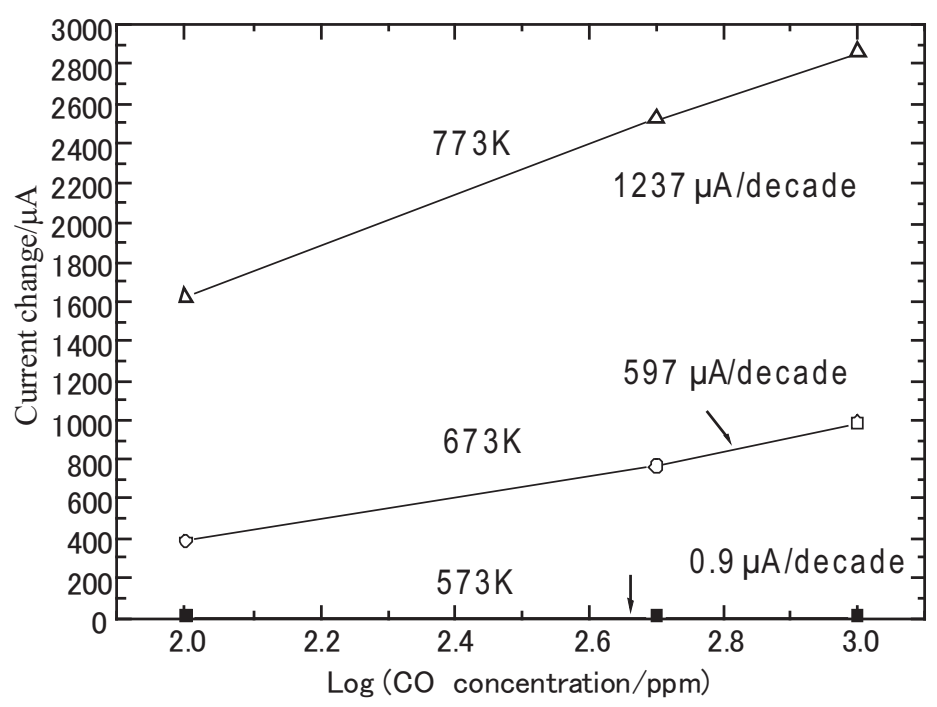

Fig. 1. Current change of the optimized sensor as a function of $\mathrm{CO}$ concentration at different temperatures. 
Figure 2 shows the current change of the sensor upon transient exposure to 1,000 ppm CO. After the current in air becomes stable, the air atmosphere was changed to $1,000 \mathrm{ppm} \mathrm{CO}$ mixed with air and the change in current was measured. After a stable oxygen pumping current was achieved against $1,000 \mathrm{ppm} \mathrm{CO}$, the sensor was exposed to air again. At $573 \mathrm{~K}$, current change was observed; however, it requires a long response time. Furthermore, recovery of the current to the original level also needs a long period. On the other hand, rather fast current response and recovery are observed at $673 \mathrm{~K}$, and the estimated $90 \%$ response times were 20 and $80 \mathrm{~s}$, respectively. On the other hand, Fig. 2(c) shows the response curve to $1,000 \mathrm{ppm} \mathrm{CO}$ followed by $500 \mathrm{ppm} \mathrm{CO}$ at $773 \mathrm{~K}$. It is seen that a much larger current change occurred and the response was also reasonably fast. However, after changing to air, the current decreased to a negative value followed by recovery to the original level. At present, the reason why the transient response shows "overshoot" is unclear; however, this response characteristic is not suitable from the viewpoint of sensor application. Therefore, despite the large sensitivity, the optimum operating temperature is considered to be $673 \mathrm{~K}$ for this sensor.

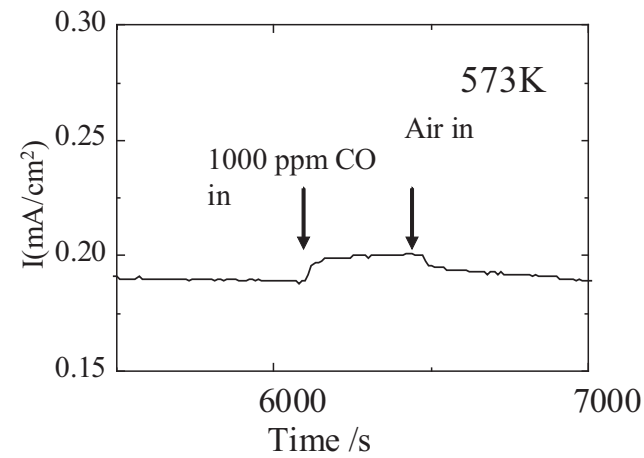

(a)

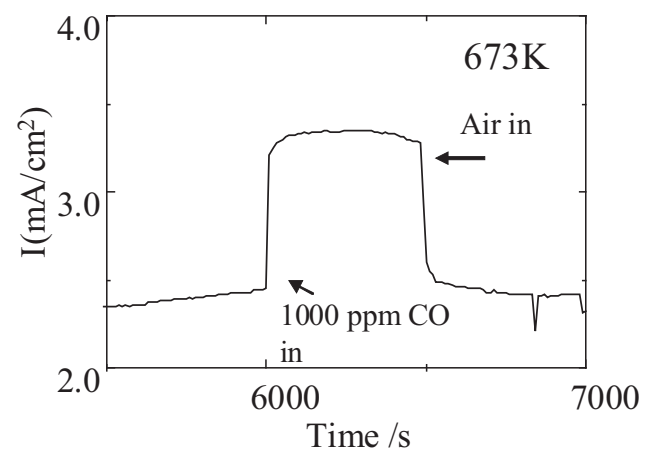

(b)

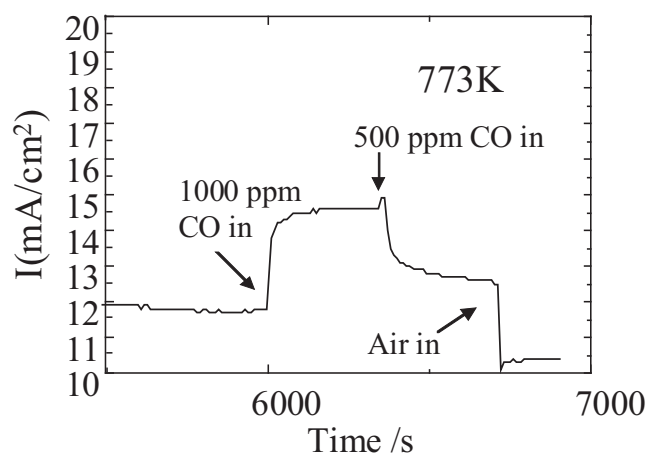

(c)

Fig. 2. Current change of the sensor upon transient exposure to 1,000 ppm CO at (a) 573, (b) 673, and (c) 573 . 
Figure 3 shows the effects of electrolyte thickness on the sensitivity to CO. It is expected that a higher sensitivity could be achieved for a sensor with a thinner electrolyte; however, the sensitivity was markedly decreased by decreasing the electrolyte thickness, although just two electrolyte thicknesses have been examined to date. At present, details of the reason for this decrease in sensitivity are unclear; however, the amount of pumping oxygen markedly improved with decreasing electrolyte thickness. Therefore, no change in oxygen partial pressure can be achieved just by the difference in electrode activity in response to $\mathrm{CO}$ oxidation. Thus, it seems that an optimum oxygen pumping current may exist for this type sensor and this might be achieved when a 0.4-mm-thick LSGM electrolyte is used.

Since changes in the oxygen pumping current may be caused by the formation of a mixed potential upon exposure to $\mathrm{CO}$, electromotive forces of the sensor were also measured. Figure 4 shows the electromotive forces (EMFs) as a function of CO concentration at different temperatures. As expected, EMF was observed upon exposure to $\mathrm{CO}$ and it monotonically increased with increasing $\mathrm{CO}$ concentration. Therefore, the change in oxygen pumping current could be caused by the formation of mixed potentials. In the case of the amperometric mode, the sensitivity increased with increasing operating temperature. However, in the case of the potentiometric mode, the sensitivity became maximum at $673 \mathrm{~K}$. The decrease in EMF at $773 \mathrm{~K}$ is simply explained on the basis of the improved activity of $\mathrm{CO}$ oxidation on the inactive electrode. Comparison of the temperature dependence showed that the amperometric mode is more useful than the potentiometric mode for $\mathrm{CO}$ sensor application because of the wider temperature range for $\mathrm{CO}$ detection and the wider detectable $\mathrm{CO}$ concentration range. In any case, it was found that the oxygen pumping current monotonically increased with $\mathrm{CO}$ concentration

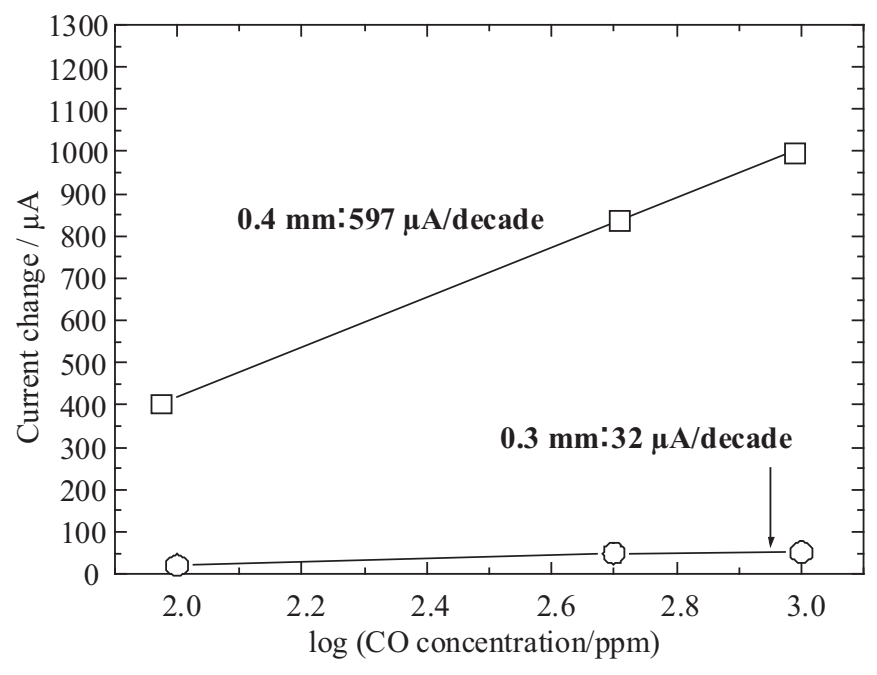

Fig. 3. Effects of electrolyte thickness on the sensitivity to CO. 


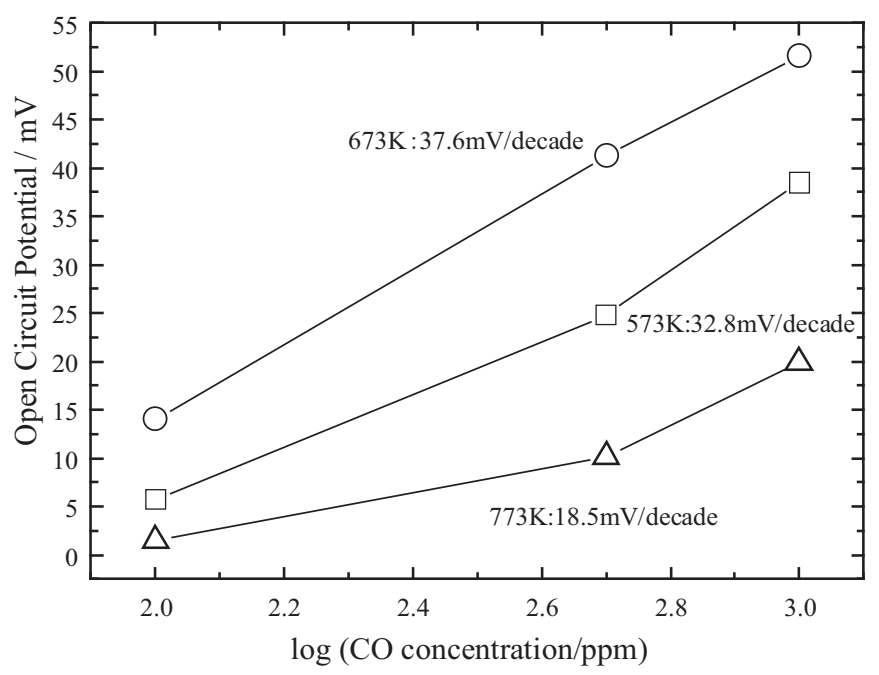

Fig. 4. Mixed potential as a function of $\mathrm{CO}$ concentration at different temperatures.

when $\mathrm{Au} / \mathrm{ITO}$ and $\mathrm{RuO}_{2} / \mathrm{LSC}$ were used for the inactive and active electrodes, respectively, for $\mathrm{CO}$ oxidation.

For the purpose of the analysis of the detection mechanism, we measured $I-V$ curves in air and 1000 ppm CO, as shown in Fig. 5. Owing to the formation of mixed potentials, the $I-V$ curves of the sensor were shifted to a higher current direction at each potential. However, the increase in current becomes larger, that is, amplified, with increasing potential. Considering the stable oxide ion conductivity of $\mathrm{LaGaO}_{3}$-based oxide in a wide $\mathrm{P}_{\mathrm{O} 2}$ range, this amplified current change at higher applied potential suggests that the electrode overpotential decreased at a higher applied potential. Because the amount of electrochemically activated oxygen increases with increasing applied potential, the surface activity of $\mathrm{CO}$ oxidation may be improved, resulting in the decreased overpotential of the electrode. In this study, we measured the conductivity by the two -probe method and we could not identify which electrode shows decreased overpotential as the applied potential increased. However, considering the slow oxidation rate on the active electrode, the decrease in overpotential might be assigned to the $\mathrm{RuO}_{2} / \mathrm{LSC}$ anode.

\subsection{Effects of additives in Ga site of $\mathrm{LaGaO}_{3}$-based electrolyte}

It is anticipated that the improvement in base current is effective for increasing the sensitivity. We studied the effects of the substitution of Ga sites with other transition metals. This is because we found that the oxide ion conductivity is improved by the partial substitution of $\mathrm{Ga}$ with $\mathrm{Co}, \mathrm{Ni}$, or Fe. Figure 6 shows the current change against $\mathrm{CO}$ concentration on the transition-metal-cation-doped LSGM electrolyte. The base current of the sensor in air was much improved by doping $\mathrm{Fe}$, Co, or $\mathrm{Ni}$ to Ga sites in LSGM. This corresponded to the improved oxide ion conductivity. On the other hand, the sensitivity to $\mathrm{CO}$ is also much improved by doping with a transition metal. 


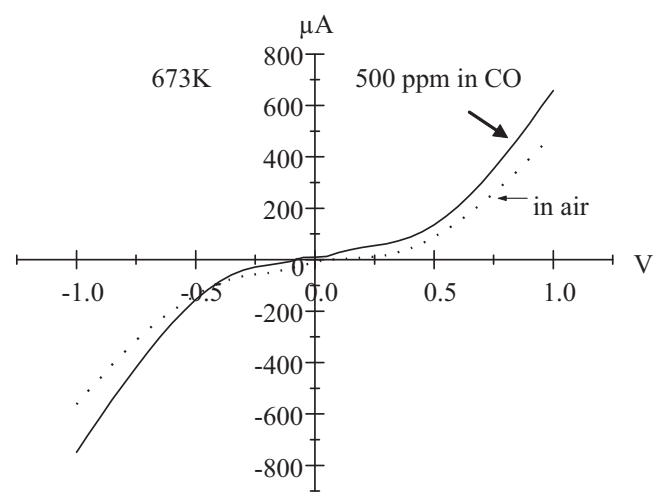

Fig. 5. $I-V$ curves of the sensor in air and $1,000 \mathrm{ppm} \mathrm{CO}$ at $673 \mathrm{~K}$.

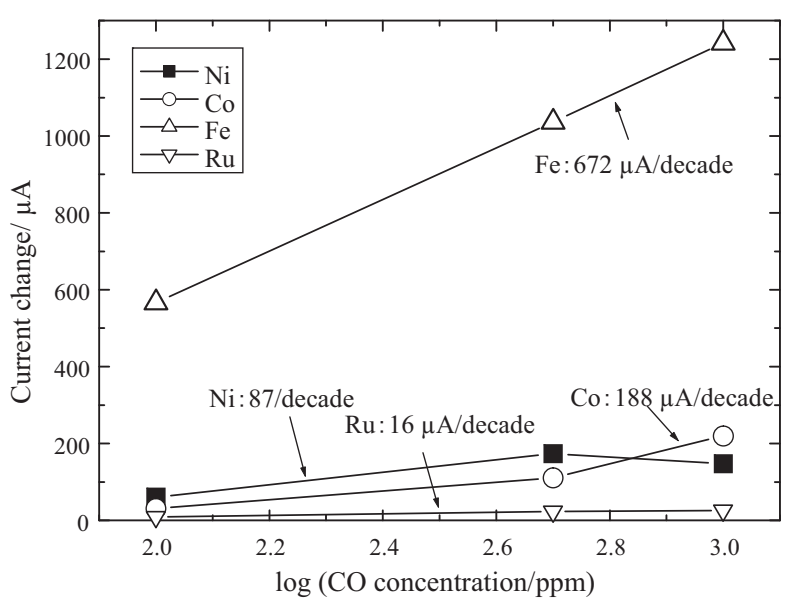

Fig. 6. Current change against $\mathrm{CO}$ concentration on the transition-metal-cation-doped LSGM electrolyte. Electrolyte: $\mathrm{La}_{0.8} \mathrm{Sr}_{0.2} \mathrm{Ga}_{0.8} \mathrm{Mg}_{0.15} X_{0.05} \mathrm{O}_{3},(X=\mathrm{Ni}, \mathrm{Co}, \mathrm{Fe}, \mathrm{Ru})$.

Evidently, the highest sensitivity among the examined samples is achieved for the sensor using Fe-doped LSGM as the electrolyte. The sensitivity is as high as $672 \mu \mathrm{A} /$ decade, which is ca. 1.5 times higher than that using the LSGM electrolyte. Therefore, doping Fe to $\mathrm{Ga}$ sites in $\mathrm{LaGaO}_{3}$ is effective for increasing the sensitivity to $\mathrm{CO}$.

Figure 7 shows the current change of the sensor using Fe-doped $\mathrm{LaGaO}_{3}$ after expoure to $\mathrm{CO}$ at different concentrations. Comparison of the results in Fig. 2 shows that not only current change but also response property is much improved by using Fe-doped $\mathrm{LaGaO}_{3}$ as the electrolyte. The response and recovery times to $1,000 \mathrm{ppm} \mathrm{CO}$ are ca. 17 and $25 \mathrm{~s}$, respectively, including the period for changing air to the sensing gas in the measurement chamber. Therefore, it can be said that the response to $\mathrm{CO}$ of this sensor is reasonably fast. 


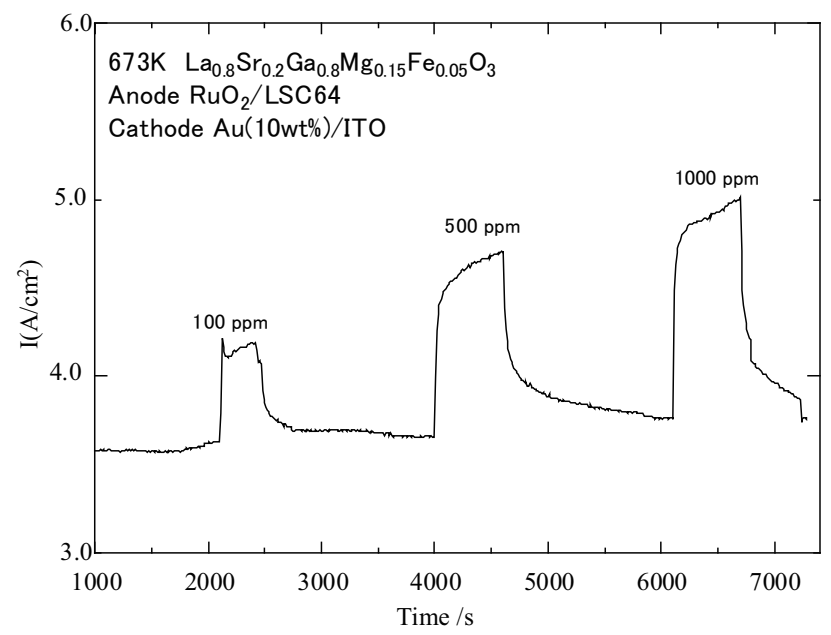

Fig. 7. Current change of the sensor using Fe-doped $\mathrm{LaGaO}_{3}$ after expure to $\mathrm{CO}$ at different concentrations.

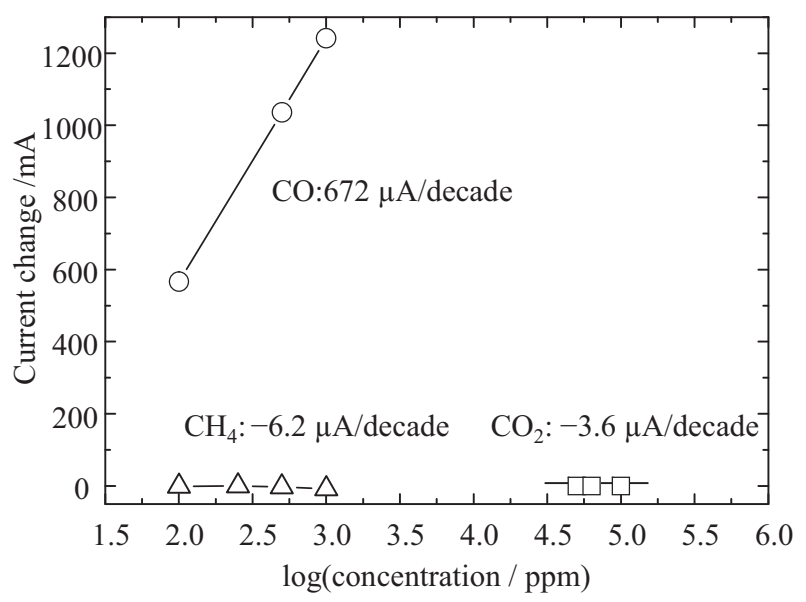

Fig. 8. Current change against $\mathrm{CH}_{4}$ and $\mathrm{CO}_{2}$ as a function of concentration.

Another important requirement for the exhaust monitoring sensor is high selectivity, in particular, to hydrocarbon and $\mathrm{CO}_{2}$. Figure 8 shows the current change against $\mathrm{CH}_{4}$ and $\mathrm{CO}_{2}$ as a function of concentration. Current change is almost negligible against $\mathrm{CH}_{4}$ and $\mathrm{CO}_{2}$, which are the major coexisting gases in the exhaust gas from a gas water heater. Therefore, this sensor shows superior selectivity towards $\mathrm{CO}$ and is suitable for monitoring $\mathrm{CO}$ directly in the exhaust gas from a water heater. To date, we have not measured the effects of water; however, it is anticipated that the effects of water may not be serious because both the electrodes are set in the same atmosphere, and also, a similar 
type of sensor that we previously studied shows low sensitivity to water. As a result, it can be concluded that the amperometric sensor using $\mathrm{Au} / \mathrm{ITO}$ and $\mathrm{RuO}_{2} / \mathrm{LSC}$ for the inactive and active electrodes, respectively, and LSGM doped with Fe for the electrolyte is highly promising as $\mathrm{CO}$ sensor for the direct monitoring of exhaust gas.

\section{Conclusions}

An amperometric $\mathrm{CO}$ sensor was studied and it was found that the oxygen pumping current in a $\mathrm{LaGaO}_{3}$-based oxide electrolyte can be used for the detection of $\mathrm{CO}$ when $\mathrm{Au} / \mathrm{ITO}$ and $\mathrm{RuO}_{2} / \mathrm{LSC}$ are used as the inactive and active electrode catalysts, respectively, against $\mathrm{CO}$ oxidation. Doping $\mathrm{Fe}$ to $\mathrm{Ga}$ sites in the $\mathrm{LaGaO}_{3}$-based perovskite oxide is also effective for achieving high sensitivity and selectivity. This sensor shows $90 \%$ response and recovery to $1,000 \mathrm{ppm} \mathrm{CO}$ at 17 and $25 \mathrm{~s}$, respectively. Furthermore, this sensor shows almost negligible sensitivity to $\mathrm{CH}_{4}$ and $\mathrm{CO}_{2}$. Therefore, it can be said that the amperometric sensor using the oxygen pumping current is highly promising as a new type of $\mathrm{CO}$ sensor for monitoring the exhaust gas from a smallscale water heater without an exhaust pipe. This is because a large-scale boiler is usually equipped with an exhaust line and exhaust gas is safely evacuated to the outside. Considering its simple structure and high selectivity, this sensor has a cost advantage and may be widely used for the selective detection of $\mathrm{CO}$ in the future.

\section{References}

1 N. Docquier and S. Candel: Prog. Energy Combust. Sci. 28 (2002) 107.

2 B. Bahrami, A. Khodadadi, M. Kazemeini and Y. Mortazavi: Sens. Actuators, B 133 (2008) 352.

3 Y. Ozaki, S. Suzuki, M. Morimitsu and M. Matsunaga: Sens. Actuators, B 62 (2000) 220.

4 N. Bârsan, J. R. Stetter, M. Findlay and W. Göpel: Sens. Actuators, B 66 (2000) 31.

5 N. Miura, K. Kanamaru, Y. Shimizu and N. Yamazoe: Solid State Ionics 40-41 (1990) 452.

6 N. Miura, G. Lu and N. Yamazoe: Solid State Ionics 136-137 (2000) 533.

7 E. L. Brosha, R. Mukundan, D. R. Brown, F. H. Garzon and J. H. Visser: Solid State Ionics 148 (2002) 61.

8 J. W. Fergus: Sens. Actuators, B 122 (2007) 683.

9 J. Wang, P. Elumalai, D. Terada, M. Hasei and N. Miura: Solid State Ionics 177 (2006) 2305.

10 Y. Shimizu, H. Nishi, H. Suzuki and K. Maeda: Sens. Actuators, B 65 (2000) 141.

11 N. Miura, T. Raisen, G. Lu and N. Yamazoe: Sens. Actuators, B 47 (1998) 84.

12 A. Dutta and T. Ishihara: Mater. Manuf. 21 (2006) 225.

13 A. Dutta, T. Ishihara and H. Nishiguchi: Chem. Mater. 16 (2004) 5198.

14 A. Dutta and T. Ishihara: Electrochem. Solid-State Lett. 8 (2005) H46.

15 A. Dutta and T. Ishihara: Sens. Actuators, B 108 (2005) 309.

16 A. Dutta, H. Nishiguchi, Y. Takita and T. Ishihara: Sens. Actuators, B 108 (2005) 368.

17 T. Ishihara, H. Matsuda and Y. Takita: J. Am. Chem. Soc. 116 (1994) 3801.

18 T. Ishihara, H. Minami, H. Matsuda, H. Nishiguchi and Y. Takita: Chem. Commun. (1996) 929.

19 X. O. Li and G. M. Kale: Sens. Actuators, B 120 (2006) 150. 